\title{
edmetic
}

Revista de Educación Mediática y TIC

\section{Nuevas ondas para a televisión universitaria: la Web TV}

En los últimos años, las universidades españolas han ido integrando de manera creciente y progresiva en sus webs corporativas portales multimedia de televisión en Internet, con el objeto de dar un impulso de mayor visibilidad a la investigación, la docencia, la vida cultural e institucional y la interacción con la comunidad $\mathrm{u}$ la sociedad, mediante la integración y uso de medios audiovisuales digitales.

Es ya visible que casi todas las universidades españolas cuentan, -o estén en proceso de contar-, con portales web de TV universitaria, entendidos como servicios de distribución universal de vídeo por Internet. Y esto es posible gracias a los avances que se han producido en cuanto a la distribución de vídeo con la utilización de tecnologías "streaming ", esto es, con la transmisión de flujo constante de datos que superan la tradicional y tediosa lenta bajada de los archivos, facilitándose de esta forma la inserción de vídeos on-line dentro de las páginas web de las Universidades, ya sean éstas las institucionales o páginas para la docencia o investigación.

Se trata, sin duda, de una novedosa forma de hacer televisión "a la carta", no exclusiva ciertamente de las universidades, ya que empresas e instituciones de la más variada tipología están haciendo uso también de estos recursos.

En suma, asistimos por primera vez a un servicio audiovisual "bajo demanda ", de no excesivo coste de implementación y desarrollo, pero que permite a los usuarios, -en nuestro caso de todos los sectores de la comunidad universitaria-, tener la posibilidad de usar los contenidos audiovisuales que se 
en cuentran en las programaciones de los portales web, con una tecnología intuitiva que permite tanto el consumo de vídeos a demanda como retransmisiones en directo.

Es momento, por tanto, de reflexionar e investigar sobre esta nueva realidad que puede promover el diseño y desarrollo de plataformas compartidas intra e interuniversitarias, que integren el conjunto de los repositorios de contenidos audiovisuales universitarios, y que ordene estos recursos de forma accesible para los usuarios. Las universidades pueden y deben compartir estas experiencias y fomentar la investigación desde ya para un uso más rentable y eficaz de estas nuevas herramientas que permitan avanzar en la definición de estándares internacionales.

Es este -la televisión universitaria- el tema central de esta nueva revista que surge ahora, "Edmetic", Revista de educación mediática y TIC, que en su volumen 1, número 1 de 2012, se centra certeramente en esta nueva realidad, que fusiona las tecnologías audiovisuales con la vida universitaria, la docencia, la investigación y la trasferencia social.

El monográfico se inicia con un trabajo del Catedrático de la Universidad de las Islas Baleares, Dr. Jesús Salinas, dedicado a "I uploaded a @YouTube video: ¿̇Una nueva perspectiva de la televisión educativa? ", que se centra en el triplete conformado por las redes, la televisión y la formación. Las tecnologías multimedia se han expansionado exponencialmente hasta el punto que consumidores, receptores y productores tienen un amplio abanico de nuevas posibilidades.

"La televisión (por internet) de la Universidad de Córdoba ", presentado por Ángel Martínez-Recio, Director del Aula Virtual de la Universidad de Córdoba Sergio Conde, Técnico del Aula Virtual, parte en la descripción de los principales sistemas de televisión por Internet así como sus aportaciones en el campo de la comunicación, para luego centrarse en la experiencia televisiva digital de esta Universidad y de su Campus de Excelencia Internacional Agroalimentario (ceiA3). 
"La televisión universitaria, el ejemplo de la Universidad de Granada ", de Dra. $M^{a}$ Asunción Romero, Profesora Contratada Doctora y la Dra. Vanesa $M^{a}$ Gámiz reflejan la experiencia la televisión universitaria de la UGR, desde un modelo de televisión vía Internet para la producción y distribución de material audiovisual. Las autoras señalan las posibilidades futuras y el potencial formativo e informativo de este canal que puede incidir con relevancia en la formación de los receptores y sobre todo en la mejora del proceso de formación de los universitarios.

En "Universidad Politécnica Radio Televisión (2000-08)", Ignacio Despujol, Técnico de Sistemas de la Universidad Politécnica de Valencia, narra la historia y el proceso de estudio, diseño y puesta en marcha de canales de radio y televisión universitarios, así como los objetivos, modelos de gestión, las plantillas, sistemas de emisión, programación, audiencia y fuentes de financiación.

"UniTV, canal de televisión de la Universidad de Huelva: hacia una TV universitaria de calidad ", del Dr. J. Ignacio Aguaded, Catedrático de la Universidad de Huelva y del Técnico Audiovisual, Daniel Ponce, recoge la experiencia de la puesta en marcha de la TV universitaria en la UHU con sistemas avanzados tecnológicamente y con una planificación que van a convertir en este medio en uno de los recursos comunicativos más significativos de la comunidad universitaria con sus conexiones internacionales a ltunes.

El Dr. Julio Cabero, Catedrático de la Universidad de Sevilla, centra su manuscrito en la "Producción audiovisual en el Secretariado de Recursos Audiovisuales y Nuevas Tecnologías de la Universidad de Sevilla (SAV) ", centro con más de dos decenios de experiencia en producción audiovisual y hoy referente obligado en el uso didácticos e institucional de las tecnologías avanzadas en el panorama universitario español.

En "UIMP-TV. Una ventana abierta al mundo", Pablo De Castro, Licenciado en Ciencias Físicas y MBA por la Escuela Europea de Negocios y Carlos Pérez del Molino, Ingeniero Consultor, analizan la plataforma de emisión de contenidos en directo $y$ en abierto de la Universidad Internacional 
Menéndez Pelayo (UIMP-TV): características técnicas del sistema, metodología de trabajo y resultados y repercusión en la comunidad UIMP 2.0 y en las redes sociales.

En definitiva, un monográfico amplio, variado y con voces múltiples que recoge experiencias, estudios, reflexiones e investigaciones que se están llevando a cabo en estos momentos en diferentes universidades españolas, en línea con las iniciativas que actualmente promueve la Asociación de Profesionales Audiovisuales Universitarios (APAU) para fomentar los contenidos audiovisuales en red.

J. Ignacio Aguaded Gómez Catedrático de la Universidad de Huelva 